ARTICLE

https://doi.org/10.1038/s41467-019-10532-2

\title{
Non-coding cis-element of Period2 is essential for maintaining organismal circadian behaviour and body temperature rhythmicity
}

\author{
Masao Doi (1) 1,7,8, Hiroyuki Shimatani ${ }^{1,7}$, Yuta Atobe ${ }^{1,7}$, lori Murai ${ }^{1,2}$, Hida Hayashi ${ }^{1}$, Yukari Takahashi', \\ Jean-Michel Fustin (1) ${ }^{1}$, Yoshiaki Yamaguchi ${ }^{1}$, Hiroshi Kiyonari ${ }^{3}$, Nobuya Koike ${ }^{4}$, Kazuhiro Yagita ${ }^{4}$, \\ Choogon Lee ${ }^{5}$, Manabu Abe ${ }^{6}$, Kenji Sakimura ${ }^{6}$ \& Hitoshi Okamura ${ }^{1,2,8}$
}

Non-coding cis-regulatory elements are essential determinants of development, but their exact impacts on behavior and physiology in adults remain elusive. Cis-element-based transcriptional regulation is believed to be crucial for generating circadian rhythms in behavior and physiology. However, genetic evidence supporting this model is based on mutations in the protein-coding sequences of clock genes. Here, we report generation of mutant mice carrying a mutation only at the $E^{\prime}$-box cis-element in the promoter region of the core clock gene Per2. The Per2 E'-box mutation abolishes sustainable molecular clock oscillations and renders circadian locomotor activity and body temperature rhythms unstable. Without the $\mathrm{E}^{\prime}$-box, Per2 messenger RNA and protein expression remain at mid-to-high levels. Our work delineates the Per2 $\mathrm{E}^{\prime}$-box as a critical nodal element for keeping sustainable cell-autonomous circadian oscillation and reveals the extent of the impact of the non-coding cis-element in daily maintenance of animal locomotor activity and body temperature rhythmicity.

\footnotetext{
${ }^{1}$ Department of Systems Biology, Graduate School of Pharmaceutical Sciences, Kyoto University, Sakyō-ku, Kyoto 606-8501, Japan. ${ }^{2}$ Laboratory of Molecular Brain Science, Graduate School of Pharmaceutical Sciences, Kyoto University, Sakyō-ku, Kyoto 606-8501, Japan. ${ }^{3}$ Laboratories for Animal Resource Development and Genetic Engineering, RIKEN Center for Biosystems Dynamics Research, Kobe 650-0047, Japan. ${ }^{4}$ Department of Physiology and Systems Bioscience, Kyoto Prefectural University of Medicine, Kyoto 602-8566, Japan. ${ }^{5}$ Department of Biomedical Sciences, College of Medicine, Florida State University, Tallahassee FL 32306, USA. ${ }^{6}$ Department of Cellular Neurobiology, Brain Research Institute, Niigata University, Niigata 951-8585, Japan. ${ }^{7}$ These authors contributed equally: Masao Doi, Hiroyuki Shimatani, Yuta Atobe. ${ }^{8}$ These authors jointly supervised this work: Masao Doi, Hitoshi Okamura. Correspondence and requests for materials should be addressed to M.D. (email: doimasao@pharm.kyoto-u.ac.jp)

or to H.O. (email: okamurah@pharm.kyoto-u.ac.jp)
} 
E vidence shows that non-coding cis-regulatory elements are as important as protein-coding sequences for determining cell identity and morphological development ${ }^{1-3}$. The degree of the effects of non-coding cis-regulatory elements on animal behavior and physiology after development, however, remains elusive. Circadian clocks generate $\sim 24 \mathrm{~h}$ rhythms in behavior and physiology, which allow organisms to anticipate and adjust to daily environmental changes. The rhythm generating mechanism of the circadian clock involves clock genes, which regulate their own transcription in a negative transcription-translation feedback loop ${ }^{4-6}$. In this canonical feedback model, non-coding cis-elements are fundamental to both initiating and closing the loop ${ }^{7-9}$. Genetic evidence supporting this model, however, is still exclusively based on the effects of mutations in the protein-coding sequences of the clock genes. Therefore, while it is tempting to speculate that the circadian clock-related non-coding cis-elements are operational for daily dynamic regulation of behavior and physiology, there is currently no direct evidence to corroborate this notion.

Notwithstanding the recent intriguing discoveries of circadian oscillations in peroxiredoxin superoxidation in transcriptionally incompetent anucleate erythrocytes ${ }^{10}$ and the expression of such cycles in the neurons in the suprachiasmatic nucleus $(\mathrm{SCN})^{11}$, the consensus conjecture regarding the mammalian clockwork supports the transcriptional feedback model. However, the literature addressing mutations or deletions in the protein-coding sequences of the clock genes cannot negate the possible contribution of post-translational (or non-genomic) clock mechanisms. Moreover, the extent of the impact of the cis-regulated transcriptional feedback cycle on establishing circadian rhythmicity in vivo remains the subject of considerable debate $e^{4,12}$, due in large part to the lack of genetic research on non-coding cis-element mutations.

In the current study, we develop mutant mice carrying a mutation in a circadian cis-acting element of the core clock gene Per2. Although Per2 was cloned as a secondary period gene in mammals, gene knockout studies revealed that Per2 mutant mice displayed a loss of circadian rhythmicity, revealing its prominent role in the mammalian molecular clockwork ${ }^{13-15}$. Moreover, familial advanced sleep phase syndrome in humans is attributed to a missense mutation in the Per2 gene ${ }^{16}$.

The Per2 E'-box sequence (5'-CACGTT-3') located near the putative transcription initiation site ${ }^{17}(-20$ to -15$)$ has been demonstrated to be the principal circadian cis-element that is sufficient to induce oscillating levels of reporter transcription via the mouse Per 2 minimal promoter ${ }^{17,18}$. The importance of this particular cis-element is further implied by the high degree of DNA sequence conservation in its flanking region between humans and mice ${ }^{17}$ and by extremely enriched clock protein binding to this element ${ }^{19}$. Publicly available genome-wide ChIPseq data highlight the predominant peak of clock protein binding activity around this $E^{\prime}$-box (see Supplementary Fig. 1).

The present study was designed to investigate the role of this unique E'-box sequence of the Per2 promoter (hereafter, Per2 $\mathrm{E}^{\prime}$-box) as a potential nodal cis-element in the mammalian clockwork. By introducing a site-specific mutation at this element in vivo, we provide empirical evidence to show that the Per $2 \mathrm{E}^{\prime}$-box is essential for maintaining cell-autonomous circadian oscillations. The cells without the Per2 E'-box cannot maintain circadian molecular oscillations in culture conditions. At the organismal level, mice lacking the Per2 promoter E'-box show destabilized locomotor activity and body temperature rhythms under altered light conditions, including constant light (LL) and experimental jet-lag conditions. Due to compensatory mechanisms in vivo, the mutant mice kept under constant dark (DD) conditions remain rhythmic but exhibit considerably shorter circadian periods than WT mice. Our data therefore define the degree of the impact of the deletion of the Per2 $\mathrm{E}^{\prime}$-box on the organismal clock: The Per $2 \mathrm{E}^{\prime}$-box is essential for the period determination of behavioral rhythms in DD conditions and for sustaining stable rhythms under LL and jet-lag conditions. These data underscore the roles of the non-coding cis-element in the regulation of daily behavior and physiology in adulthood.

\section{Results}

Generation of Per2 E'-box mutant mice. We developed mutant mice harboring a targeted mutation in only the Per $2 \mathrm{E}^{\prime}$-box. To do this, we used the piggyBac $(P B)$ transposase tool for genome engineering because it allows for seamless removal of the $P B$ flanked marker cassette $(P B-\mathrm{Neo})$ from the host genome after the mutation is introduced (Fig. 1a). Conventional methods that rely on the Cre/lox $\mathrm{P}$ or Flp/FRT system leave behind a single lox $\mathrm{P}$ - or FRT-derived ectopic sequence after marker excision. Such a footprint sequence could affect promoter architecture and/or enhancer communication of the target gene ${ }^{20}$. The PB transposase (PBase) $/ P B$ system circumvents this problem ${ }^{21}$ (see Fig. $1 \mathrm{~b}-\mathrm{d})$. Southern blot analysis confirmed that the $P B$-neomycin cassette was deleted without re-integration into the host genome (Fig. 1c). The footprint-free disappearance of the marker cassette was further confirmed by DNA sequencing (Fig. 1d). To reduce the confounding effects of a mixed genetic background, the mutant mice were backcrossed with C57BL/6J mice until microsatellite markers covering all individual chromosomes were congenic to the C57BL/6J strain (see Supplementary Fig. 2). The targeted mutation of the $\mathrm{E}^{\prime}$-box sequence was finally verified by DNA sequencing using homozygous mutant mice (Fig. 1d). Chromatin immunoprecipitation (ChIP) assays using homozygous mutant mouse liver, sampled at $4 \mathrm{~h}$ intervals for $24 \mathrm{~h}$ under DD conditions, revealed that the clock proteins PER1, CRY1, CRY2, and CLOCK had consistently low binding levels to the mutated Per2 promoter (Fig. 1e). In a control experiment with WT $(+/+)$ samples, the peak binding levels of PER1, CRY1, CRY2, and CLOCK to the Per2 promoter were observed at CT12, CT4, CT20, and CT8, respectively, consistent with previous reports ${ }^{19,22}$. These results confirmed that Per2 $\mathrm{E}^{\prime}$-box function was abolished in the mutant mice.

Per2 $\mathrm{E}^{\prime}$-box is essential to maintain cellular circadian oscillations. To investigate the role of the Per2 $\mathrm{E}^{\prime}$-box in maintaining cellular oscillation, we generated primary fibroblast cultures from WT $\left(\right.$ Per $\left.2 \mathrm{E}^{\prime+/+}\right)$ and mutant $\left(\right.$ Per $\left.2 \mathrm{E}^{\prime \mathrm{m} / \mathrm{m}}\right)$ mouse lung tissues and monitored circadian fluctuations in the PER2 protein levels over 80 $h$ (Fig. 2a). As expected, the endogenous PER2 protein in synchronized WT cells displayed characteristic circadian oscillations in both abundance and electrophoretic mobility, which continued over multiple cycles under constant culture conditions ${ }^{23}$ (Fig. 2a). In contrast, Per $2 \mathrm{E}^{\prime \mathrm{m}} / \mathrm{m}$ cells failed to maintain normal PER2 protein oscillations (Fig. 2a). It is important to note that the mutant cells could competently form the first surge of PER2 expression after synchronization (4-12 h). However, following a subsequent increase $(28 \mathrm{~h})$, PER2 expression in the mutant cells remained at mid-tohigh levels and eventually lost apparent circadian variation after 60 h (see also Supplementary Fig. 3). Electrophoretic migration rhythms also disappeared from the mutant cells (Fig. 2a). The relative intensities of the three major bands of the PER2 protein remained unchanged in the $P e r 2 \mathrm{E}^{\prime \mathrm{m} / \mathrm{m}}$ cells. The post-translational rhythms were thus affected either directly or indirectly by the mutation of the $E^{\prime}$-box. We experimentally confirmed that the protein-coding sequences of PER2 and known clock protein kinases and phosphatases were unaffected in our mutant mice. These results indicate that the $\mathrm{E}^{\prime}$-box is indispensable for maintaining normal PER2 protein oscillations. 
a
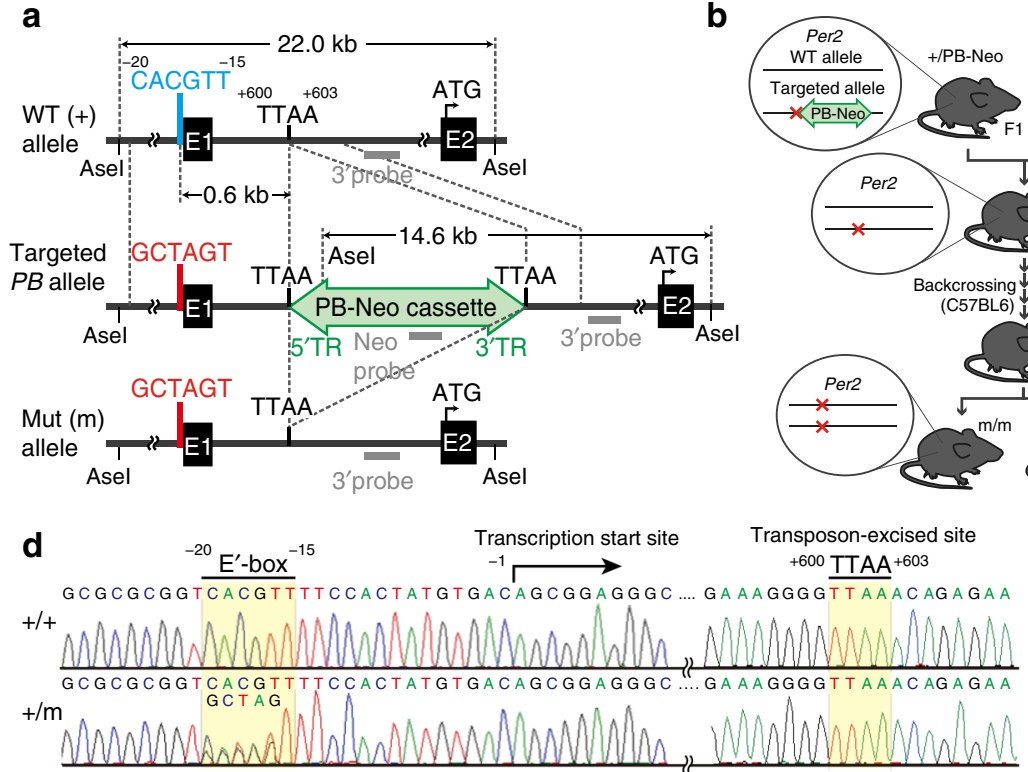

b

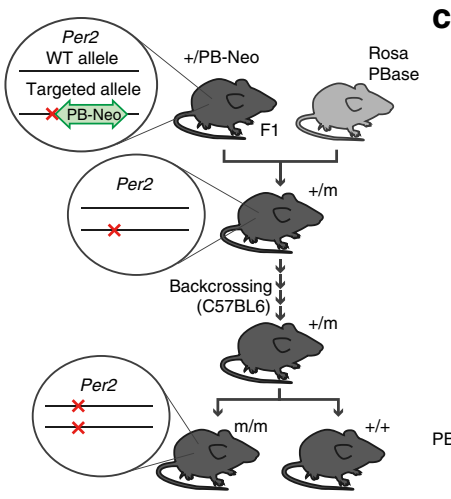

C

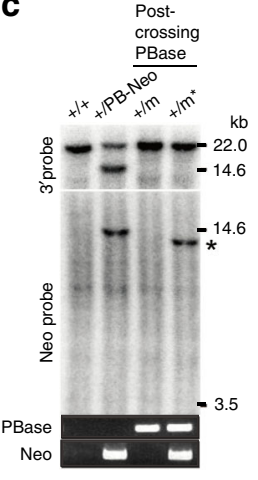

e
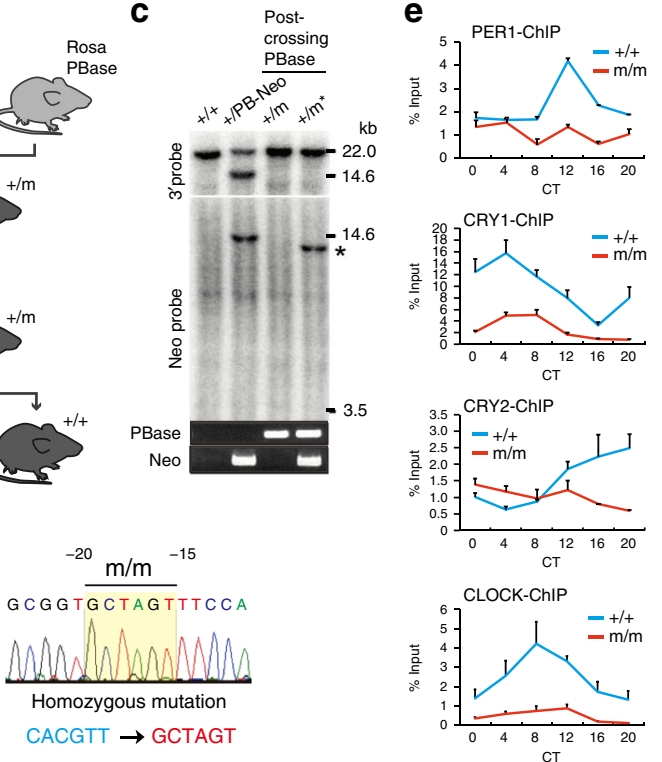

Fig. 1 Generation of mice carrying a targeted mutation at Per2 $\mathrm{E}^{\prime}$-box. a Genome modification strategy using the piggyBac transposon. The CACGTT Per2 E'-box was mutated to GCTAGT. Top line, genome architecture of the mouse Per2 gene; E1, exon 1; E2, exon 2; Blue, wildtype E'-box; Red, mutated E '-box; Green, piggyBac transposon carrying a neomycin-resistant gene (PB-Neo cassette) inserted at a genomic TTAA site (+600 to +603 ); Gray bars, Southern blot probes. Numbering shows the position relative to the putative transcription start site $(+1)$. $\mathbf{b}$ Interbreeding scheme. Mice heterozygous for the targeted allele (+/PB-Neo) were intercrossed with ROSA26-PBase mice. The resultant mutant mice without the marker cassette $(+/ \mathrm{m})$ were backcrossed into the C57BL/6J strain. c Southern blot and PCR analysis showing the insertion ( $+/ \mathrm{PB}-\mathrm{Neo})$ and excision $\left(+/ \mathrm{m}\right.$ and $\left.+/ \mathrm{m}^{\star}\right)$ of the piggyBac transposon. ${ }^{*}$, a reintegrated PB-Neo fragment. $\mathbf{d}$ Genomic DNA sequences of WT $(+/+)$ and Per2 $\mathrm{E}^{\prime}$-box mutant $(+/ \mathrm{m}$ and $\mathrm{m} / \mathrm{m})$ mice, illustrating the precise mutation of the $E^{\prime}$-box and seamless excision of the PB-Neo cassette from the TTAA site. Heterozygous $(+/ \mathrm{m})$ mouse sequences exhibit dual signals for CACGTT and GCTAGT at the E'-box. e ChIP values for WT $(+/+)$ and homozygous mutant $(\mathrm{m} / \mathrm{m})$ mouse liver sampled at $4 \mathrm{~h}$ intervals for $24 \mathrm{~h}$ on the first day in DD. Values are means \pm s.e.m. of three technical replicates. Source data for $(\mathbf{c})$ and $(\mathbf{e})$ are provided as a Source Data file

a

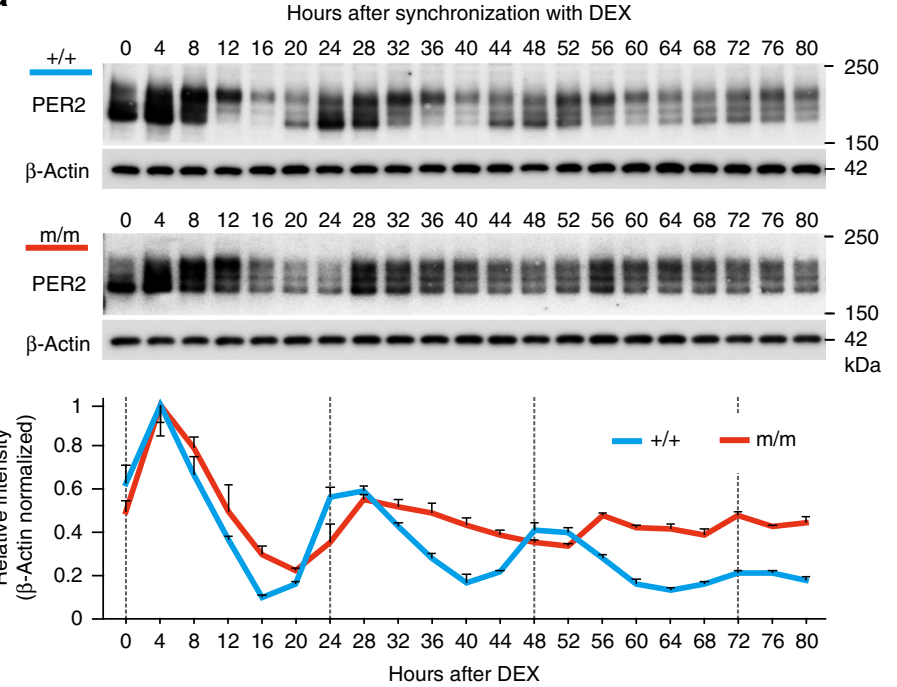

b
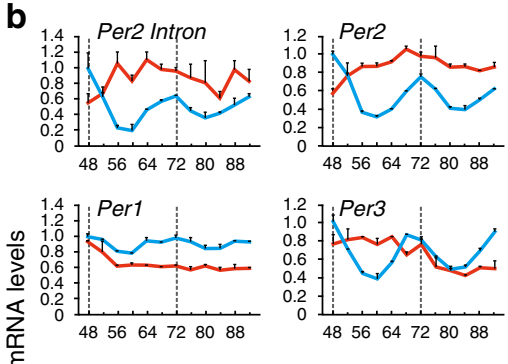

$$
\begin{aligned}
& -+/+ \\
& -\mathrm{m} / \mathrm{m}
\end{aligned}
$$

$$
485664728088
$$
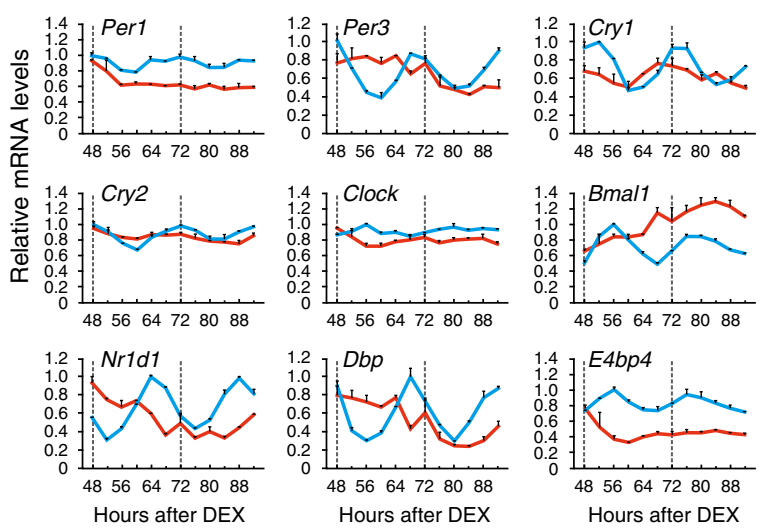

Fig. 2 Per2 $\mathrm{E}^{\prime}$-box is essential for maintaining cell-autonomous circadian oscillations. a Temporal profiles of PER2 protein expression in Per2E' $+/+$ and Per2E $\mathrm{m} / \mathrm{m}$ fibroblasts. Representative immunoblots and normalized densitometry values $(n=3$, mean \pm s.e.m.) are shown. $\mathbf{b}$ mRNA profiling of clock genes in Per2 $\mathrm{E}^{\prime+/+}$ and Per $2 \mathrm{E}^{\prime} \mathrm{m} / \mathrm{m}$ fibroblasts ( $n=2$, for each data point). For Per2, both intron and exon RNA were analyzed. The data are presented as the mean \pm variation. Source data are provided as a Source Data file

In the $\operatorname{Per} 2 \mathrm{E}^{\prime \mathrm{m}} / \mathrm{m}$ cells, we observed that both Per2 mRNA and pre-mRNA (intronic RNA) levels remained constitutively high, with values exceeding those of the circadian peak in the WT cells at $72 \mathrm{~h}$ (Fig. 2b). Thus, Per2 transcription remains active even without this particular $E^{\prime}$-box sequence in the promoter. Moreover, extensive mRNA profiling revealed that the effects of the mutation of the Per2 $\mathrm{E}^{\prime}$-box were not limited to Per2 transcription. The dysfunctional Per2 E'-box also abolished the circadian expression of other clock genes and output genes, including Per1, Per3, Cry1, Cry2, Bmal1, Nr1d1, Dbp, and E4bp4 (Fig. 2b). These pervasive effects of the mutation provide evidence that the Per2 E'-box is a fundamental cis-element that maintains normal molecular clock oscillations. 

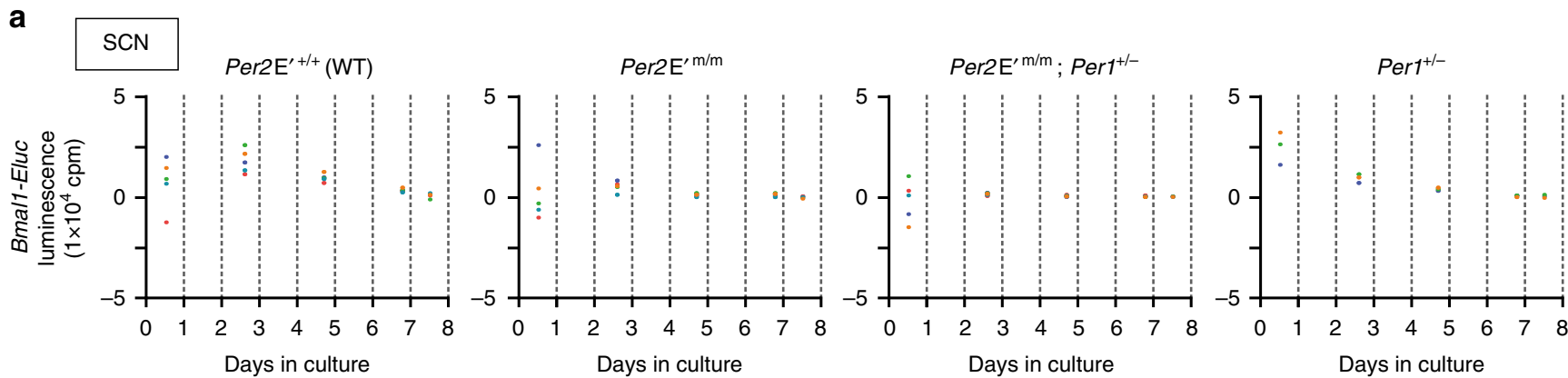

b
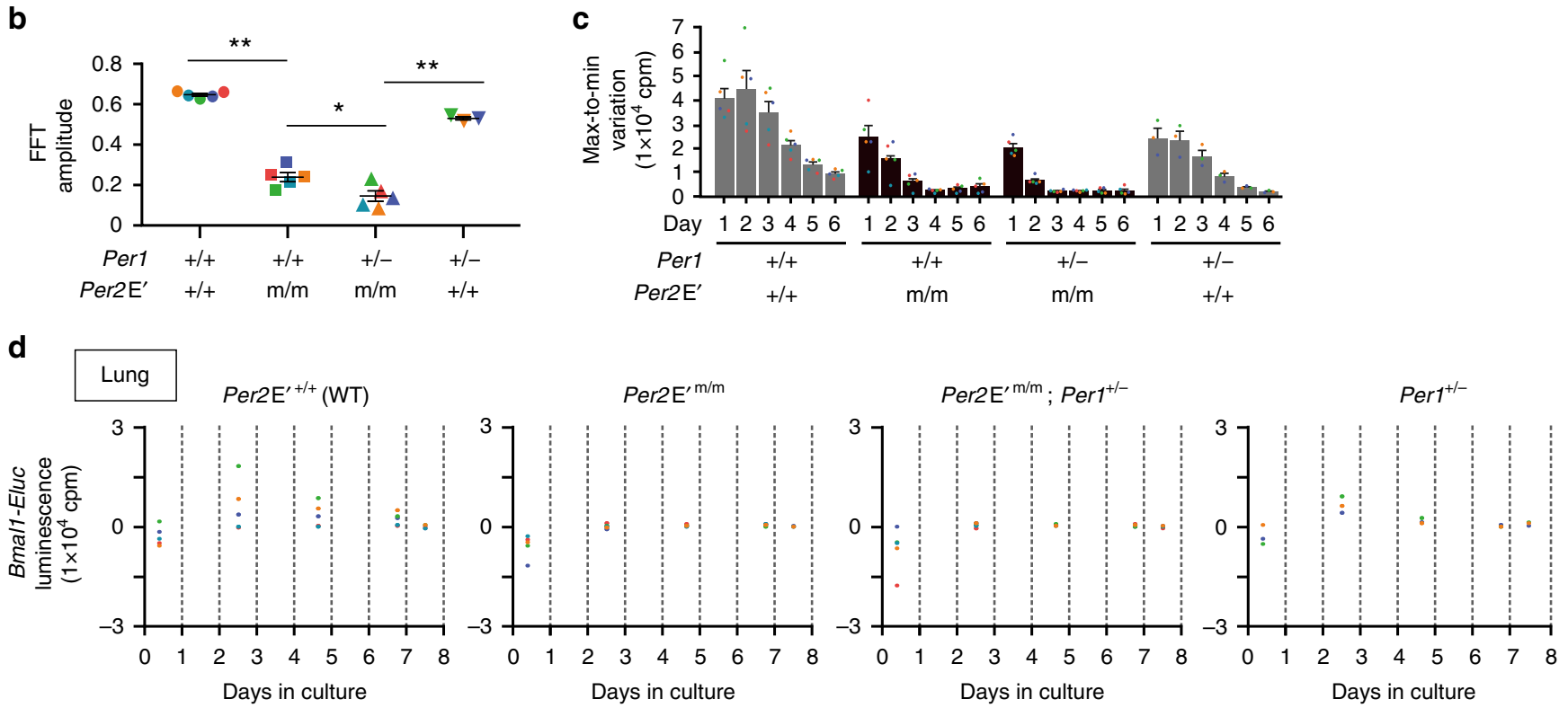

e
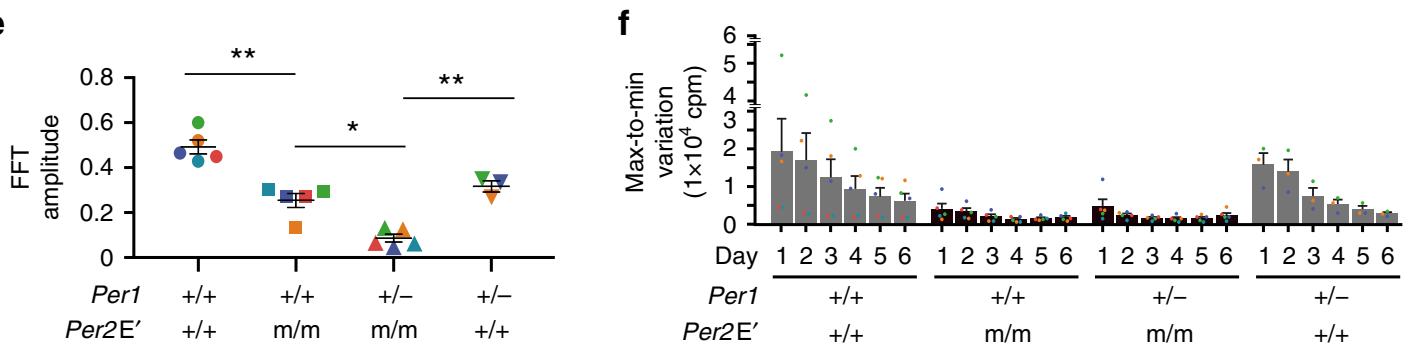

Fig. 3 Per2 $\mathrm{E}^{\prime}$-box is essential for sustainable Bmal1 oscillations in SCN and lung explants. a Bmal1-Eluc bioluminescence traces of ex vivo SCN cultures from Per2E $\mathrm{E}^{\prime /+}(n=5), \operatorname{Per} 2 \mathrm{E}^{\prime \mathrm{m}} / \mathrm{m}(n=5), \operatorname{Per} 2 \mathrm{E}^{\prime \mathrm{m}} / \mathrm{m} ; \operatorname{Per} 1^{+/-}(n=5)$, and Per1 ${ }^{+/-}(n=3)$ mice. Averaged de-trended data are shown. b FFT amplitude of (a). ${ }^{\star} P<0.05,{ }^{\star \star} P<0.001$, one-way ANOVA, Bonferroni post hoc test. c Daily max-to-min variations of (a). The data are presented as the mean \pm s.e.m. d Bmal1-Eluc bioluminescence traces of lung tissue explant cultures from Per2 $\mathrm{E}^{\prime+/+}(n=5), \operatorname{Per} 2 \mathrm{E}^{\prime \mathrm{m}} / \mathrm{m}(n=5), \operatorname{Per} 2 \mathrm{E}^{\prime \mathrm{m}} / \mathrm{m} ; \operatorname{Per}^{+/-}(n=5)$, and Per1 ${ }^{+/-}$ $(n=3)$ mice. Averaged de-trended data are shown. e FFT amplitude of $(\mathbf{d}) .{ }^{\star} P<0.05,{ }^{\star \star} P<0.001$, one-way ANOVA, Bonferroni post hoc test. $\mathbf{f}$ Daily maxto-min variations of $(\mathbf{d})$. The data are presented as the mean \pm s.e.m. Source data for $(\mathbf{c})$ and $(\mathbf{f})$ are provided as a Source Data file

Per2 $\mathrm{E}^{\prime}$-box is essential to maintain molecular oscillations in the SCN. The SCN in the hypothalamus is the primary regulator of daily rhythms of behavior and physiology in mammals ${ }^{24,25}$. We next examined the effect of the Per2 E'-box mutation on the SCN clock. To study the molecular rhythms in the SCN, we used a Bmal1 promoter-driven luciferase reporter (Bmal1-Eluc) ${ }^{26}$, as it allowed the assessment of molecular rhythms that are not a simple reflection of the Per2 loop. In agreement with previous reports 27 , organotypic SCN slices prepared from control mice (Per2 $\mathrm{E}^{\prime+l+}$; Bmal1-Eluc) displayed persistent circadian rhythms of luminescence, which continued for over a week in culture (Fig. 3a, see also Supplementary Fig. 4). In contrast, all tested SCN slices from the Per $2 \mathrm{E}^{\prime}$-box mutant mice $\left(\right.$ Per $2 \mathrm{E}^{\prime \mathrm{m}} / \mathrm{m}_{;}$BmallEluc) displayed attenuated rhythms of luminescence, which were damped within 2-3 cycles (Fig. 3a). Fast Fourier transform (FFT) analysis of the de-trended waveforms of days 1.5-7.5 (Fig. 3b) confirmed the reduced rhythmicity in the Per $2 \mathrm{E}^{\prime \mathrm{m}} / \mathrm{m}$ SCN. This finding indicated the relevance of the Per2 $\mathrm{E}^{\prime}$-box in maintaining normal molecular circadian oscillations in the SCN. Nevertheless, detectable rhythms were noted in the attenuated Per $2 \mathrm{E}^{\prime} \mathrm{m} / \mathrm{m}$ SCN slices over the initial 2-3 cycles (Fig. 3a). These remaining rhythms were likely dependent on Per1, because SCN explants from Per $2 \mathrm{E}^{\prime \mathrm{m} / \mathrm{m}}$; Per 1 heterozygous null mice $\left(\operatorname{Per} 2 \mathrm{E}^{\prime \mathrm{m}} / \mathrm{m}\right.$; Per1 $1^{+/}$;Bmal1-Eluc) exhibited even fewer persistent rhythms, which were damped within 2 cycles (Fig. 3a-c). Importantly, similar attenuation of Bmal1-Eluc rhythmicity by Per $2 \mathrm{E}^{\prime} \mathrm{m} / \mathrm{m}$ and further by $P e r 1^{+/}$could be reproduced in cultures of lung (Fig. 3d-f) and adrenal explants (Supplementary Fig. 4), 
a

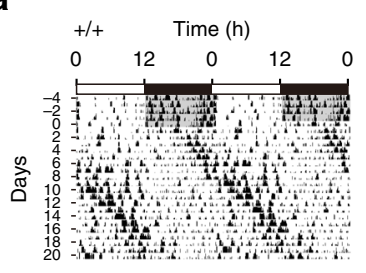

b

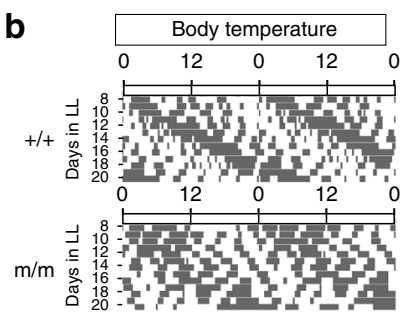

Days in LL $\overline{1-15} \overline{4-18} \overline{7-21}$

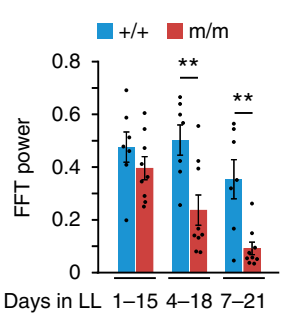

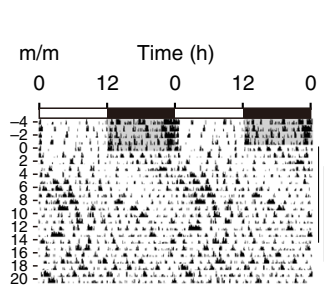

Time (h)
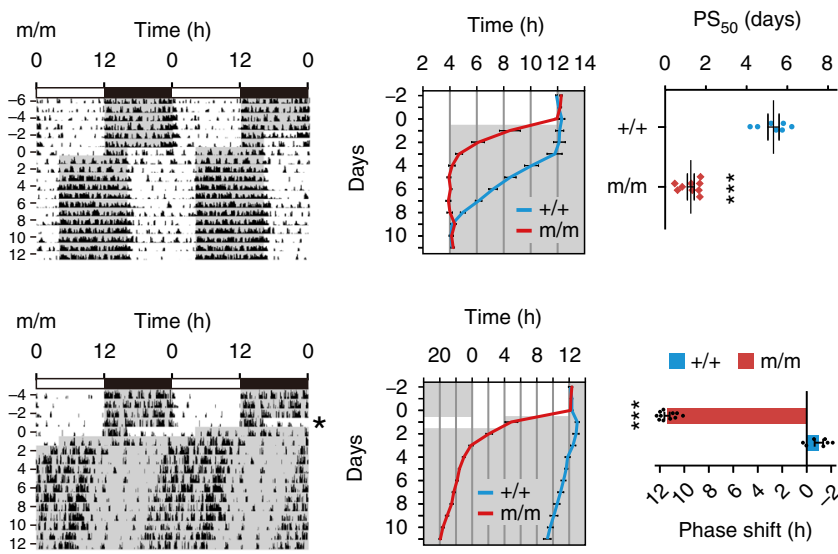

\begin{tabular}{ccccc}
$\mathrm{m} / \mathrm{m}$ & \multicolumn{3}{c}{ Time $(\mathrm{h})$} \\
0 & 12 & 0 & 12 & 0
\end{tabular}

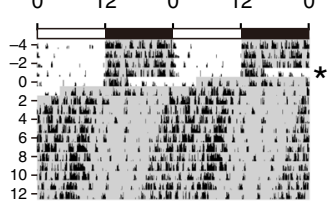

d

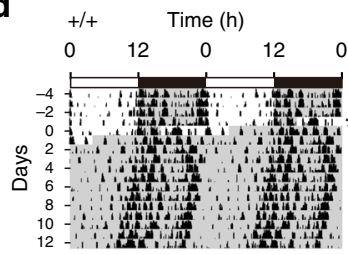

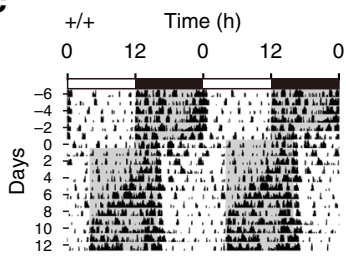

Fig. 4 a Destabilized circadian locomotor activity and body temperature rhythms of Per2 E'-box mutant mice. Representative locomotor activity records of Per2 $\mathrm{E}^{\prime+/+}$ and Per2 $\mathrm{E}^{\prime} \mathrm{m} / \mathrm{m}$ mice under light/dark (LD) followed by constant light (LL). The graph shows changes in FFT power in LL. ${ }^{\star \star} P<0.01$, two-way

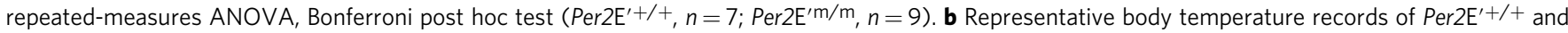
Per $2 E^{\prime m} / \mathrm{m}$ mice in $\mathrm{LL}$. The mean temperature of the entire data series was calculated, and the data points above the mean are plotted. Rayleigh plots show phase distribution of elevated body temperature on days 7-21 $(n=3$, each genotype). Data from independent animals are color-coded. Arrow length reflects the $r$-value of each distribution. ${ }^{\star} P<0.05$, two-tailed unpaired $t$-test. $\mathbf{c}$ Representative records of locomotor activity (left) and plots of activity onset

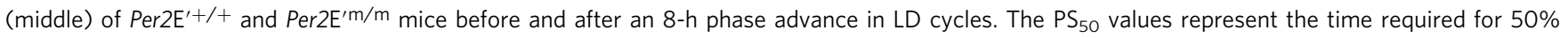
phase-shift (right). ${ }^{\star \star \star} P<0.0001$, two-tailed unpaired t-test (Per2 $\mathrm{E}^{\prime+/+}, n=7 ;$ Per2 $\mathrm{E}^{\prime} \mathrm{m} / \mathrm{m}, n=9$ ). d Representative locomotor activity records (left), activity onset (middle), and magnitude of phase-shift (right) of Per2 $\mathrm{E}^{\prime+/+}$ and Per2 $\mathrm{E}^{\prime} \mathrm{m} / \mathrm{m}$ mice subjected to an 8 -h phase advance on day 1 and released to DD. ${ }^{\star \star \star} P<0.0001$, two-tailed unpaired $t$-test $\left(P e r 2 \mathrm{E}^{\prime+/+}, n=7 ; P\right.$ er2 $\left.\mathrm{E}^{\prime \mathrm{m}} / \mathrm{m}, n=11\right)$. The data are the mean \pm s.e.m. Source data are provided as a Source Data file

confirming the importance of the Per2 $\mathrm{E}^{\prime}$-box in keeping sustained molecular circadian oscillations not only for the SCN but also for the peripheral tissues.

Destabilized organismal rhythms of animal lacking Per2 $\mathbf{E}^{\prime}$-box. Finally, to assess the effects of the mutation at the behavioral level, C57BL/6J-backcrossed WT and Per2 $\mathrm{E}^{\prime} \mathrm{m} / \mathrm{m}$ mice were housed in a 12-h light:12-h dark (LD) cycle and then subjected to DD, LL, or experimental jet-lag conditions. Actograms of the animals in the respective conditions were acquired (see Supplementary Figs. 5-9). Interestingly, mutant mice kept in DD showed overt circadian locomotor activity rhythms, although with a significantly shortened free-running circadian period relative to WT mice (WT vs. Per2 $2 \mathrm{E}^{\prime \mathrm{m}} / \mathrm{m}: 23.71 \pm 0.02 \mathrm{~h}$ vs. 23.50 $\pm 0.02 \mathrm{~h}$; see Supplementary Fig. 5). This contrast with the in vitro data suggests that a compensatory mechanism functions in vivo. We thus examined the circadian behavior of $\operatorname{Per}^{-1-} ; \operatorname{Per} 2 \mathrm{E}^{\prime \mathrm{m}} / \mathrm{m}$ double-deficient mice (see Supplementary Fig. 6). Although their period length was unstable and changed gradually over extended exposure to constant darkness, Per1 ${ }^{-1-}$; Per $2 \mathrm{E}^{\prime \mathrm{m} / \mathrm{m}}$ mice displayed behavioral rhythms over 40 days. With analogy, Drosophila strains expressing period or timeless under a constitutive promoter were reported to show behavioral rhythms with an altered period length 12,28 . These data suggest that organisms might have a compensatory mechanism to mitigate defective transcriptional feedback regulation ${ }^{4,24,29}$.
Compared to the modest phenotype in $\mathrm{DD}$, we observed unstable rhythmicity of the mutant mice in LL (Fig. 4a). When placed in LL for 3 weeks, WT subjects $(n=7)$ stayed rhythmic with a period longer than $24 \mathrm{~h}$, which is consistent with data from previous reports ${ }^{30,31}$. However, none of the $P e r 2 \mathrm{E}^{\prime \mathrm{m}} / \mathrm{m}$ mice $(n=9)$ remained rhythmic (Fig. 4a, see also Supplementary Fig. 7); all tested mutant mice displayed behaviors characterized by a gradual decrease in the power of rhythmicity (FFT spectrogram, Fig. 4a). Since light has a negative masking effect on locomotor activity, we measured core body temperature fluctuations and confirmed that the body temperature recapitulated the reduced rhythmicity of the mutant mice in LL conditions (Fig. 4b, Rayleigh vector length of WT vs. Per $2 \mathrm{E}^{\prime \mathrm{m}} / \mathrm{m}_{\mathrm{m}} 0.64 \pm 0.06$ vs. $0.42 \pm 0.02$ ).

The Per2 E'-box mutant mice were also distinct under experimental jet-lag conditions (Fig. 4c, see also Supplementary Fig. 8). When the ambient LD cycle was advanced by $8 \mathrm{~h}$, WT mice re-entrained progressively over 8 to 9 days $^{32}$. In contrast, the Per2 $2 \mathrm{E}^{\prime \mathrm{m} / \mathrm{m}}$ mice adapted to the new cycle within 2-3 days. The $50 \%$ phase-shift value $\left(\mathrm{PS}_{50}\right)^{32}$, measured from activity onset, indicated a rapidity of $5.33 \pm 0.28$ days for WT mice and $1.26 \pm$ 0.17 days for $P e r 2 \mathrm{E}^{\prime \mathrm{m}} / \mathrm{m}$ mice (Fig. 4c). Notably, the difference between the two genotypes was even pronounced when the animals were exposed to a single 8-h light advance, followed by DD conditions (Fig. 4d, see also Supplementary Fig. 9). Under this light regime, all tested mutant mice shifted forward by approximately $12 \mathrm{~h}$, which is nearly $180^{\circ}$ out of phase in a $24-\mathrm{h}$ 
cycle, relative to WT mice (Fig. 4d). The underlying mechanism of this extremely large shift is unknown. While this could be due to an indirect effect of the weak clock, a limit cycle oscillator mode $^{33}$ predicts that a reduced-amplitude pacemaker in the mutant mice (reduced radius of the limit cycle) could have this effect $^{34}$. We also noticed that after a light pulse exposure, the mutant mice show a slightly enhanced Per2 mRNA induction in the SCN (see Supplementary Fig. 10). This perhaps also partly contributes to the enhanced resetting of the mutant mice.

\section{Discussion}

Non-coding cis-regulatory elements are known to play a critical role in development, but their precise effects on daily behavior and physiology in adulthood remain elusive. The present study was designed to provide genetic evidence for the roles of the circadian cis-element in vivo. Despite the presence of compensatory mechanisms in vivo, our work shows that the Per2 E'-box is essential for maintaining optimal locomotor activity rhythms under LL conditions and enabling the phase of the clock to resist abrupt shifts in $\mathrm{LD}$ cycling. In general, adapting to new $\mathrm{LD}$ cycles is rarely instantaneous and requires repeated $24 \mathrm{~h}$ cycles. However, the Per2 E'-box mutant mice adapted to a new phase immediately. These data elucidate the impact of the deletion of the non-coding cis-element in daily maintenance of behavioral activity in adulthood.

In addition, our cell culture data reinforce the concept that circadian clock phenotypes are more drastic at the cellular level than the organismic level ${ }^{4,24}$. Per2 $\mathrm{E}^{\prime}$-box mutation leads to unsustainable gene expression rhythms in organotypic $\mathrm{SCN}$ slices and cultured peripheral tissues and fibroblasts. These observations substantiate the general conjecture that cis-regulatory element-based gene transcription is essential for sustaining cellular clock oscillations.

Not surprisingly, the overall behavioral phenotypes of the Per2 $\mathrm{E}^{\prime}$-box mutant mice reveal that the Per2 $\mathrm{E}^{\prime}$-box is not an absolute requirement for behavioral rhythm generation. Under DD conditions, its deletion affects only the circadian period (Supplementary Figs. 5 and 6), a phenotype analogous to that observed in transgenic Drosophila strains expressing period or timeless via a constitutive promoter ${ }^{12,28}$. At the gene expression level, Per2 expression in the liver and SCN in the DD-kept mutant mice in vivo was still rhythmic, albeit with an increased baseline (see Supplementary Fig. 11). These observations suggest that organisms have a compensatory mechanism to mitigate defective transcriptional feedback regulation. Correspondingly, previous studies demonstrate that behavioral rhythms do not necessarily reflect cellular clock phenotypes ${ }^{29,35-37}$; superior circadian performance of behavioral rhythmicity has been observed in several clock gene mutant mice, compared to tissue cultures obtained from the same animal strains ${ }^{29}$. In vivo multicellular and/or inter-organ systemic circuitry might compensate for poor core clock function within individual cells ${ }^{4}$. In this regard, it is worth noting that systemic extracellular signals are known to affect the Per2 promoter via non-E'-box cis-regulatory elements, such as $\mathrm{Ca}^{2+} / \mathrm{cAMP}$ response element $(\mathrm{CRE})^{38}$ and glucocorticoid response element $(\mathrm{GRE})^{39}$. Extracellular circadian feedback pathways through these non- $\mathrm{E}^{\prime}$-box elements might contribute to the compensation mechanisms in vivo ${ }^{40,41}$.

Our work differs from transgenic studies in which non-native promoters are used ${ }^{12,17}$. Transgenic studies and rescue experiments can be affected by shorter promoter regulatory sequences and position effects. In comparison, native promoters are characterized by endogenous enhancer elements and normal chromatin structure, allowing for the preservation of regulation by epigenetic factors, which are known to be crucial for controlling transcription ${ }^{5}$. Under these near-native conditions, we noticed that the deletion of the Per2 E'-box leads to accumulation of Per2 mRNA and protein in cultured fibroblasts. Constitutively un-suppressed transcription of Per2 likely underlies the constant accumulation of PER2 protein and resultant compromised gene expression rhythms in the mutant cells.

Cis-element provides a place where both active and repressive transcription complexes are recruited. The net effect of its absence thus seems context-dependent. The question of this context specificity is still unresolved in the field of transcription and chromatin remodeling. Particularly, in our case, the mechanism(s) that allows the continued transcription of Per2 without relying on the $\mathrm{E}^{\prime}$-box is still unknown. It is possible that native chromatin structure of the Per 2 might permit its transcription. It is also conceivable that other circadian cis-elements on the Per2 promoter, such as D-box and CRE, might contribute to the basal transcription of $P e r 2^{9,18,42}$. In this regard, the continued expression of Per2 might reflect a confounding effect of being chronically deficient in the functional E'-box. Given that Per2 is under regulation of interlocked feedback cycles 6,9 , remaining Per2 transcription might be a homeostatic consequence of a nonfunctional clock in the mutant cells. A complete understanding of circadian regulation of Per2 in vivo under native conditions remains a challenge for future study.

Genome-wide association studies recently identified many noncoding variants that account for human chronotype ${ }^{43-45}$. Given the physiologic relevance of the Per2 cis-element, a targeted point mutation strategy would facilitate hypothesis-driven approaches to understand the extent of the impact of the non-coding elements on the daily physiology and pathophysiology of the organism.

\section{Methods}

Generation of the Per2 E'-box mutant mice. The CACGTT E'-box sequence located in the Per 2 promoter $\left(-20\right.$ to $-15 ;+1$, the putative transcription start site $\left.{ }^{17}\right)$ was targeted. Note that numbering of the relative position of the $E^{\prime}$-box sequence will change according to the definition of the transcription initiation site ${ }^{17,18}$ (see also RefSeq database in the UCSC genome browser: https://genome.ucsc.edu/). CACGTT was mutated to GCTAGT, because this change is reported to abrogate CLOCK:BMAL1-mediated activation of Per2 promoter activity in vitro ${ }^{17}$. We employed piggyBac $(P B)$ transposon-based gene engineering system ${ }^{46,47}$, because conventional methods relying on Cre/lox $\mathrm{P}$ or Flp/FRT systems leave behind a single lox $\mathrm{P}$ or $F R T$-derived sequence after excision, which causes the creation of 'footprint' (residual ectopic sequence) that might affect promoter architecture and/ or enhancer communication of target gene ${ }^{48}$. The targeting vector to generate $P B$ mutant allele of Per2 was constructed by using a Red/ET recombination system (Gene Bridges). The bacterial artificial chromosome (BAC) containing Per 2 was obtained from BACPAC Resources at the Children's Hospital and Research Center at Oakland (RP23-343F13). With a Red/ET cloning method (Gene Bridges), a 10 kb genomic region of Per $2(-5899$ to $+4,103 ;+1$, the putative transcription start site $^{17}$ ) that corresponds to the region of $6.5 \mathrm{~kb}$ upstream (long arm) and $3.5 \mathrm{~kb}$ downstream (short arm) of the Per2 E'-box (-20/-15) was cloned into a vector containing a diphtheria toxin A gene (pDTA vector). Then, a DNA amplicon of Per2 $(-90$ to +650$)$ that contains a mutated $E^{\prime}$-box (GCTAGT) at $-20 /-15$ was obtained by fusion PCR, and this was further modified by inserting a $P B$ terminal repeat sequence $\left(5^{\prime} \mathrm{TR}\right.$ and $\left.3^{\prime} \mathrm{TR}\right)$-flanked neomycin cassette $(P B-\mathrm{NEO})$ into the TTAA quadruplet sequence of Per $2(+600 /+603)$. With a second-round Red/ET cloning, this fragment was recombined into the $10-\mathrm{kb}$ Per2 BAC/pDTA vector. The resultant Per 2 targeting vector was verified by DNA sequencing.

Gene targeting was carried out with TT2 embryonic stem cell. Germline transmission was verified by PCR and Southern blotting. The Per $2 \mathrm{E}^{\prime}$-box mut $P B$ NEO F1 mice (Accession No. CDB1060K: http://www2.clst.riken.jp/arg/mutant\% 20 mice\%20list.html) were intercrossed with ROSA26-PBase knock-in mice ${ }^{49}$ (a gift from A. Bradley, Wellcome Trust Sanger Institute, UK) to remove the $P B-\mathrm{NEO}$ cassette from the genome. A seamless excision of the cassette was verified by direct DNA sequencing. Genotypes of the $E^{\prime}$-box were determined by DNA sequencing and/or TaqMan qPCR with the following probes: WT, 5'-FAM-TAG TGG AAA ACG TGA CCG C-MGB-3', and mutant, $5^{\prime}$-VIC-TAG TGG AAA CTA GCA CCG C-MGB-3'. The use of different reporter dyes with separated emission wavelength maxima (FAM and VIC) enabled concurrent detection of the two alleles in a single PCR with a common primer set for Per2: forward, 5'-GGA GCC GCT AGT CCC AGT AG-3'; reverse, 5'-AGG TGG CAC TCC GAC CAA T-3'. The established mutant mice were backcrossed into the $\mathrm{C} 57 \mathrm{BL} / 6 \mathrm{~J}$ background using a markerassisted breeding (i.e., speed congenic) approach ${ }^{50,51}$. Where specified, Per $2 \mathrm{E}^{\prime} \mathrm{m} / \mathrm{m}$ mice were intercrossed with mice carrying a Bmall-Eluc reporter ${ }^{26,27,52}$ and/or Per1-deficient mice ${ }^{15}$ of C57BL/6J background (The Jackson Laboratory, 10491). 
All animal experiments were conducted in compliance with ethical regulations in Kyoto University and performed under protocols approved by the Animal Care and Experimentation Committee of Kyoto University and Institutional Animal Care and Use Committee of RIKEN Kobe Branch.

ChIP. ChIP assays were performed with technical replicates ${ }^{19,53}$ : We repeated chromatin/DNA shearing with equal amounts of aliquots from the same liver nuclear sample. In brief, whole liver sample was homogenized with ice-cold PBS (4 $\mathrm{ml} /$ liver) and cross-linked in two steps using first $2 \mathrm{mM}$ disuccinimidyl glutarate for $20 \mathrm{~min}$ then $1 \%$ methanol-free ultrapure formaldehyde for $5 \mathrm{~min}$ at room temperature. Glycine was added for $5 \mathrm{~min}$ in $125 \mathrm{mM}$ final concentration. The homogenates $(\sim 5 \mathrm{ml} /$ liver $)$ were mixed with ice-cold $2.3 \mathrm{M}$ sucrose buffer $(10 \mathrm{ml} /$ liver) containing $125 \mathrm{mM}$ glycine, $10 \mathrm{mM}$ HEPES pH 7.6, $15 \mathrm{mM} \mathrm{KCl}, 2 \mathrm{mM}$ EDTA, $0.15 \mathrm{mM}$ spermine, $0.5 \mathrm{mM}$ spermidine, $0.5 \mathrm{mM}$ DTT, and $0.5 \mathrm{mM}$ PMSF and layered on top of a $5 \mathrm{ml}$ cushion of $1.85 \mathrm{M}$ sucrose. Ultracentrifugation was performed at $105,000 \times g$ for $1 \mathrm{~h}$ at $4{ }^{\circ} \mathrm{C}$ with a Beckman SW28 rotor. The resultant nuclear pellets were stored at $-80^{\circ} \mathrm{C}$ until use. The nuclei were resuspended in 1.5 $\mathrm{ml}$ per liver of IP buffer (10 mM Tris-HCl pH 7.5, $150 \mathrm{mM} \mathrm{NaCl}, 1 \mathrm{mM}$ EDTA, $1 \%$ Triton X-100, 0.1\% sodium deoxycholate, 1 mM PMSF, protease inhibitor cocktail) and divided equally into three aliquots, which were each separately sonicated around $15 \mathrm{~s}$ for 80 times at $4{ }^{\circ} \mathrm{C}$ using a Bioruptor UCW-201TM apparatus (Tosho Denki, Japan). For each reaction, $10 \mu \mathrm{g}$ fragmented chromatin was resuspended in $500 \mu \mathrm{l}$ of IP buffer, pre-cleared with protein A-agarose, and incubated overnight at $4{ }^{\circ} \mathrm{C}$ with the following antibody: for PER1, $2 \mu \mathrm{l}$ of anti-mPER1 rabbit antiserum (Millipore, \#AB2201); for CRY1, $1 \mu \mathrm{g}$ of affinity-purified anti-mCRY1 guinea pig polyclonal antibody 19,54; for CRY2, $1 \mu \mathrm{g}$ of affinity-purified anti-mCRY2 guinea pig polyclonal antibody ${ }^{19,54}$; and for CLOCK, $1 \mu \mathrm{g}$ of anti-mCLOCK mouse monoclonal antibody ${ }^{55}$ (MBL, \#D349-3). To collect immunocomplexes, $40 \mu \mathrm{l}$ of Protein A/G Plus-agarose beads (Santa Cruz) were added and further incubated at $4{ }^{\circ} \mathrm{C}$ for $1.5 \mathrm{~h}$. After beads washing and DNA elution ${ }^{53}$, eluted DNA fragments were purified with Qiaquick Nucleotide Removal Kit (Qiagen) and subjected to qPCR analysis with Per2 E'-box primers (forward primer, 5'-GAG GTG GCA CTC CGA CCA ATG-3'; reverse primer, 5'-GCG TCG CCC TCC GCT GTC AC-3) and Per2 $-4.5 \mathrm{~kb}$ negative binding site primers (forward primer, 5 '-CCA CAC GGT ACT CAG CGG GC-3'; reverse primer, 5'-GGG TCA CTG CGA GCC TTG CC-3').

Cell culture and immunoblotting. WT and $\operatorname{Per} 2 \mathrm{E}^{\prime \mathrm{m}} / \mathrm{m}$ primary fibroblasts were isolated from the lung tissue of adult male mice according to a protocol established by Seluanov et al. ${ }^{56}$. Cells used for time course assay were between passages 4 and 6. Dispersed cells were uniformly plated in 24 -well plates at a density of $1 \times 10^{5}$ cells per well and cultured for 2 days prior to synchronization, for which cells were treated with dexamethasone (DEX, final concentration, $200 \mathrm{nM}$ ) for $3 \mathrm{~h}$, followed by medium refreshment at Time0. Cells were harvested every $4 \mathrm{~h}$ in either TRIzol reagent (Invitrogen) for RNA analysis or $2 \times$ Laemmli buffer for Western blot analysis. Immunoblotting was performed using an affinity-purified anti-mPER2 rabbit polyclonal antibody ${ }^{23}$ (final concentration, $2 \mu \mathrm{g} \mathrm{ml}^{-1}$ ) and $\beta$-Actin antibody (A5441, Sigma, 1:1000).

RNA extraction and RT-qPCR. Total RNA was extracted with RNeasy kit (Qiagen) and converted to cDNA with SuperScript VILO cDNA Synthesis kit (Invitrogen). qPCR was run on a BioMark HD System (Fluidigm) with a 48.48 Fluidigm BioMark Dynamic Array chip (Fluidigm) ${ }^{57}$. TaqMan probe and primer sets were as follows; for Per2, probe, FAM-AGG CAC CTC CAA CAT GCA ACG AGC CTAMRA, forward primer (fw): 5'-GCA CAT CTG GCA CAT CTC GG-3', reverse primer (rv): 5'-TGG CAT CAC TGT TCT GAG TGT C-3'; for Per2 intron, probe, FAM-TGG AGC CCA CCG CAG ACA GCC C-TAMRA, fw: $5^{\prime}$-CCT CTC ACC TCA TGC CCT TTT AG-3', rv: 5'-CTG CTC AGA CCA ACA GAT TTA TCA-3'; for Per1, probe, FAM-AGC CCC TGG CTG CCA TGG-TAMRA, fw: 5'-CAG GCT TCG TGG ACT TGA GC-3', rv: 5'-AGT GGT GTC GGC GAC CAG-3'; for Per3, probe, FAM-TTC TGC TCA TCA CCA CCC TGC GGT TCC-TA

MRA, fw: 5'-ACA GCT CTA CAT CGA GTC CAT G-3', rv: 5'-CAG TGT CTG AGA GGA AGA AAA GTC-3'; for Cryl, probe, FAM-TGA TCC ACA GGT CAC CAC GAG TCA GGA A-TAMRA, fw: 5'-TAG CCA GAC ACG CGG TTG-3', rv: 5'-AGC AGT AAC TCT TCA AAG ACC TTC A-3'; for Cry2, probe, FAM-AGG TCT CTC ATA GTT GGC AAC CCA GGC-TAMRA, fw: $5^{\prime}$-TGG ACA AGC ACT TGG AAC GG-3', rv: 5'-GGC CAG TAA GGA ATT GGC ATT C-3'; for Clock, probe, FAM-ACC CAG AAT CTT GGC TTT TGT CAG CAG C-TAMRA, fw: 5'TGG CAT TGA AGA GTC TCT TCC TG-3', rv: 5'-GAG ACT CAC TGT GTT GAT ACG ATT G-3'; for Bmall, probe, FAM-CGC CAA AAT AGC TGT CGC CCT CTG ATC T-TAMRA, fw: 5'-GTA CGT TTC TCG ACA CGC AAT AG-3', rv: 5'-GTA CCT AGA AGT TCC TGT GGT AGA-3'; for Nrld1, probe, FAM-CCC TGG ACT CCA ATA ACA ACA CAG GTG G-TAMRA, fw: 5'-TCA GCT GGT GAA GAC ATG ACG-3', rv: 5'-GAG GAG CCA CTA GAG CCA ATG-3'; for $D b p$, probe, FAM-CGG CTC CCA GAG TGG CCC GC-TAMRA, fw: $5^{\prime}$-CGG CTC TTG CAG CTC CTC-3', rv: 5'-GTG TCC CTA GAT GTC AAG CCT G-3'; for E4bp4, probe, FAM-CAG GGA GCA GAA CCA CGA TAA CCC ATG A-TAMRA, fw: 5'-CGC CAG CCC GGT TAC AG-3', rv: 5'-CAT CCA TCA ATG GGT CCT TCT G-3'; for Rplp0, probe, FAM-TGG CAA TCC CTG ACG CAC C GC C-TAMRA, fw: 5'-GCG TCC TCG TTG GAG TGA C-3', rv: 5'-AAG TAG T
TG GAC TTC CAG GTC G-3'. for Gapdh, probe, FAM-CGG CCA AAT CCG TTC ACA CCG ACC-TAMRA, fw: 5'-GAG ACG GCC GCA TCT TCT T-3', rv: $5^{\prime}$-TCT CCA CTT TGC CAC TGC A-3'. Values were normalized to average expression of Rplp0 and Gapdh.

Real-time bioluminescence recording and data analysis. Tissues from mice carrying a Bmal1 promoter-driven luciferase reporter $(\text { Bmall-ELuc })^{26}$ were harvested from adult (2-3 months-old) male mice between ZT10-12 and cultured according to a published method ${ }^{58}$. In brief, brains were sliced coronally into 400 $\mu \mathrm{m}$ sections, and the paired SCN, which contains minimal volumes of the non$\mathrm{SCN}$, were cultured 59 . The lungs were cut into a small piece $\left(\sim 2 \times 2 \times 0.3 \mathrm{~mm}^{3}\right)^{59}$. The adrenal glands were sliced into a section of $0.3 \mathrm{~mm}$ thickness. All tissues were cultured separately on a Millicell membrane (PICMORG50, Millipore) with DMEM medium containing10 mM HEPES ( $\mathrm{pH} 7.2$ ), 2\% B27 (Invitrogen) and 1 $\mathrm{mM}$ luciferin, in 35-mm dish, and air sealed. Bioluminescence recording was started immediately upon placement in culture with a dish-type luminometer (Kronos Dio, ATTO) maintained at $37^{\circ} \mathrm{C}$. Luminescence was measured for $3 \mathrm{~min}$ for each dish at 30 -min intervals. The data were smoothed using a $2 \mathrm{~h}$ moving average and further detrended by subtracting a $24 \mathrm{~h}$ running average for FFT analysis. A fourth-order Blackman-Harris window was applied before the power spectrum calculation. The spectrum was normalized to an integral of one by dividing each of its elements by the sum of all elements. Circadian rhythmicity was defined as relative spectral power density at the peak in the circadian range (20-30 h). The peak values represent the power within a frequency band of 0.009 .

Locomotor activity recording and data analysis. C57BL/6J-backcrossed $\operatorname{Per} 2 \mathrm{E}^{\prime} \mathrm{m} /+$ mice were intercrossed to produce homozygous mutant $\left(\operatorname{Per} 2 \mathrm{E}^{\prime} \mathrm{m} / \mathrm{m}\right)$ and WT $\left(\right.$ Per $\left.2 \mathrm{E}^{\prime+/+}\right)$ progenies using in vitro fertilization. We used adult male mice (8- to 10 -week old). The animals were housed individually in light-tight, ventilated closets under indicated lighting conditions with ad libitum access to food and water. Locomotor activity was recorded via passive infrared sensors (PIRs, FA-05F5B Omron) with 1-min resolution and analyzed with CLOCKLAB software (Actimetrics ${ }^{60}$. Free-running period in DD was determined with $\chi^{2}$ periodogram, based on animal behaviors in a 40-day interval taken 3 days after the start of DD condition. Rhythmicity in LL was evaluated using FFT-Relative Power (CLOCKLAB, Actimetrics). A fourth-order Blackman-Harris window was applied before the power spectrum calculation. The spectrum was normalized to an integral of one by dividing each of its elements by the sum of all elements. Circadian rhythmicity was defined as relative spectral power density at the peak in the circadian range (20-36 h). The peak values represent the power within a frequency band of 0.006 . Speed of behavioral re-entrainment was evaluated using $50 \%$ phase-shift value $\left(\mathrm{PS}_{50}\right)^{32,61}$. To determine $\mathrm{PS}_{50}$, sigmoidal dose-response curve with variable slope, $Y=$ Bottom $+($ Top - Bottom $) /\left(1+10^{(\log \text { PS50 }-X) \text { Hillslope })}\right.$, was fitted to the onset time points using GraphPad Prism software.

Body temperature recording and data analysis. Precalibrated temperature data loggers (Thermochron iButtons, DS1921H, Maxim) were surgically implanted to the peritoneal cavity of mice under general anaesthesia. After a week of recovery in LD, mice were transferred into LL. The iButtons were programmed for collecting temperature data every $20 \mathrm{~min}$. For data analysis, the mean temperature of the entire data series during days 7 to 21 in LL was calculated, and the data points above the mean were displayed in double-plotted format using CLOCKLAB. For circular plot, data were detrended by subtracting a $24 \mathrm{~h}$ running average, and periods of top 20\% temperature were deployed in Rayleigh format using Oriana 4 software (Kovacs Computer Services, UK). CT12 was extrapolated from the onsets of locomotor activity during days 3-6. Phase distribution was assessed by mean vector length (Oriana 4)

Reporting summary. Further information on research design is available in the Nature Research Reporting Summary linked to this article.

\section{Data availability}

The source data underlying Figs. 1c, e, 2a, b, 3c, f, 4a-d, Supplementary Figs. 3, 4e, 6b, c 10a, b, 11a, b are provided as a Source Data file. All the other data supporting the findings of this study are available within the article and its Supplementary Information files and from the corresponding authors upon reasonable request. A reporting summary for this article is available as a Supplementary Information file.

Received: 6 October 2018 Accepted: 16 May 2019

Published online: 12 June 2019

\section{References}

1. Kvon, E. Z. et al. Progressive loss of function in a limb enhancer during snake evolution. Cell 167, 633-642 e611 (2016). 
2. Indjeian, V. B. et al. Evolving new skeletal traits by cis-regulatory changes in bone morphogenetic proteins. Cell 164, 45-56 (2016).

3. Whyte, W. A. et al. Master transcription factors and mediator establish superenhancers at key cell identity genes. Cell 153, 307-319 (2013).

4. Rosbash, M. et al. Transcriptional feedback and definition of the circadian pacemaker in Drosophila and animals. Cold Spring Harb. Symp. Quant. Biol. 72, 75-83 (2007).

5. Masri, S. \& Sassone-Corsi, P. The circadian clock: a framework linking metabolism, epigenetics and neuronal function. Nat. Rev. Neurosci. 14, 69-75 (2013).

6. Takahashi, J. S. Transcriptional architecture of the mammalian circadian clock. Nat. Rev. Genet. 18, 164-179 (2017).

7. Hao, H., Allen, D. L. \& Hardin, P. E. A circadian enhancer mediates PERdependent mRNA cycling in Drosophila melanogaster. Mol. Cell. Biol. 17, 3687-3693 (1997).

8. Gekakis, N. et al. Role of the CLOCK protein in the mammalian circadian mechanism. Science 280, 1564-1569 (1998).

9. Ueda, H. R. et al. System-level identification of transcriptional circuits underlying mammalian circadian clocks. Nat. Genet. 37, 187-192 (2005).

10. O'Neill, J. S. \& Reddy, A. B. Circadian clocks in human red blood cells. Nature 469, 498-503 (2011)

11. Edgar, R. S. et al. Peroxiredoxins are conserved markers of circadian rhythms. Nature 485, 459-464 (2012).

12. Yang, Z. \& Sehgal, A. Role of molecular oscillations in generating behavioral rhythms in Drosophila. Neuron 29, 453-467 (2001).

13. Zheng, B. et al. The mPer2 gene encodes a functional component of the mammalian circadian clock. Nature 400, 169-173 (1999).

14. Zheng, B. et al. Nonredundant roles of the mPer1 and mPer2 genes in the mammalian circadian clock. Cell 105, 683-694 (2001).

15. Bae, K. et al. Differential functions of mPer1, mPer2, and mPer3 in the SCN circadian clock. Neuron 30, 525-536 (2001).

16. Toh, K. L. et al. An hPer2 phosphorylation site mutation in familial advanced sleep phase syndrome. Science 291, 1040-1043 (2001).

17. Yoo, S. H. et al. A noncanonical E-box enhancer drives mouse Period2 circadian oscillations in vivo. Proc. Natl Acad. Sci. USA 102, 2608-2613 (2005).

18. Akashi, M., Ichise, T., Mamine, T. \& Takumi, T. Molecular mechanism of cellautonomous circadian gene expression of Period2, a crucial regulator of the mammalian circadian clock. Mol. Biol. Cell 17, 555-565 (2006).

19. Koike, N. et al. Transcriptional architecture and chromatin landscape of the core circadian clock in mammals. Science 338, 349-354 (2012).

20. Yusa, K. Seamless genome editing in human pluripotent stem cells using custom endonuclease-based gene targeting and the piggyBac transposon. Nat. Protoc. 8, 2061-2078 (2013).

21. Yusa, K., Rad, R., Takeda, J. \& Bradley, A. Generation of transgene-free induced pluripotent mouse stem cells by the piggyBac transposon. Nat. Methods 6, 363-369 (2009).

22. Rey, G. et al. Genome-wide and phase-specific DNA-binding rhythms of BMAL1 control circadian output functions in mouse liver. PLoS Biol. 9, e1000595 (2011).

23. Tainaka, M., Doi, M., Inoue, Y., Murai, I. \& Okamura, H. Circadian PER2 protein oscillations do not persist in cycloheximide-treated mouse embryonic fibroblasts in culture. Chronobiol. Int. 35, 132-136 (2018).

24. Herzog, E. D., Hermanstyne, T., Smyllie, N. J. \& Hastings, M. H. Regulating the Suprachiasmatic Nucleus (SCN) Circadian Clockwork: interplay between cell-autonomous and circuit-level mechanisms. Cold Spring Harb. Perspect. Biol. 9, a027706 (2017).

25. Okamura, H. Suprachiasmatic nucleus clock time in the mammalian circadian system. Cold Spring Harb. Symp. Quant. Biol. 72, 551-556 (2007).

26. Noguchi, T., Ikeda, M., Ohmiya, Y. \& Nakajima, Y. A dual-color luciferase assay system reveals circadian resetting of cultured fibroblasts by co-cultured adrenal glands. PLoS ONE 7, e37093 (2012).

27. Ono, D. et al. Dissociation of Perl and Bmall circadian rhythms in the suprachiasmatic nucleus in parallel with behavioral outputs. Proc. Natl Acad. Sci. USA 114, E3699-E3708 (2017).

28. Kadener, S., Menet, J. S., Schoer, R. \& Rosbash, M. Circadian transcription contributes to core period determination in Drosophila. PLoS Biol. 6, el19 (2008).

29. Liu, A. C. et al. Intercellular coupling confers robustness against mutations in the SCN circadian clock network. Cell 129, 605-616 (2007)

30. Pittendrigh, C. S. \& Daan, S. A functional analysis of circadian pacemakers in nocturnal rodents. III. Heavy water and constant light: homeostasis of frequency? J. Comp. Physiol. A 106, 267-290 (1976).

31. Ohta, H., Yamazaki, S. \& McMahon, D. G. Constant light desynchronizes mammalian clock neurons. Nat. Neurosci. 8, 267-269 (2005).

32. Yamaguchi, Y. et al. Mice genetically deficient in vasopressin V1a and V1b receptors are resistant to jet lag. Science 342, 85-90 (2013).

33. Winfree, A. T. The Geometory of Biological Time, (Springer, New York, 2000).
34. Vitaterna, M. H. et al. The mouse Clock mutation reduces circadian pacemaker amplitude and enhances efficacy of resetting stimuli and phaseresponse curve amplitude. Proc. Natl Acad. Sci. USA 103, 9327-9332 (2006).

35. Liu, C., Weaver, D. R., Strogatz, S. H. \& Reppert, S. M. Cellular construction of a circadian clock: period determination in the suprachiasmatic nuclei. Cell $\mathbf{9 1}$, 855-860 (1997).

36. Herzog, E. D., Takahashi, J. S. \& Block, G. D. Clock controls circadian period in isolated suprachiasmatic nucleus neurons. Nat. Neurosci. 1, 708-713 (1998).

37. Nakamura, W., Honma, S., Shirakawa, T. \& Honma, K. Clock mutation lengthens the circadian period without damping rhythms in individual SCN neurons. Nat. Neurosci. 5, 399-400 (2002).

38. Travnickova-Bendova, Z., Cermakian, N., Reppert, S. M. \& Sassone-Corsi, P Bimodal regulation of mPeriod promoters by CREB-dependent signaling and CLOCK/BMAL1 activity. Proc. Natl Acad. Sci. USA 99, 7728-7733 (2002).

39. So, A. Y., Bernal, T. U., Pillsbury, M. L., Yamamoto, K. R. \& Feldman, B. J. Glucocorticoid regulation of the circadian clock modulates glucose homeostasis. Proc. Natl Acad. Sci. USA 106, 17582-17587 (2009).

40. Hastings, M. H., Maywood, E. S. \& O'Neill, J. S. Cellular circadian pacemaking and the role of cytosolic rhythms. Curr. Biol. 18, R805-R815 (2008).

41. Parsons, M. J. et al. The regulatory factor ZFHX3 Modifies Circadian function in SCN via an AT motif-driven axis. Cell 162, 607-621 (2015).

42. O’Neill, J. S., Maywood, E. S., Chesham, J. E., Takahashi, J. S. \& Hastings, M. $\mathrm{H}$. cAMP-dependent signaling as a core component of the mammalian circadian pacemaker. Science 320, 949-953 (2008).

43. Lane, J. M. et al. Genome-wide association analysis identifies novel loci for chronotype in 100,420 individuals from the UK Biobank. Nat. Commun. 7 , 10889 (2016)

44. $\mathrm{Hu}$, Y. et al. GWAS of 89,283 individuals identifies genetic variants associated with self-reporting of being a morning person. Nat. Commun. 7, 10448 (2016).

45. Jones, S. E. et al. Genome-wide association analyses in 128,266 individuals identifies new morningness and sleep duration loci. PLoS Genet. 12, e1006125 (2016).

46. Ding, S. et al. Efficient transposition of the piggyBac (PB) transposon in mammalian cells and mice. Cell 122, 473-483 (2005).

47. Wang, W. et al. Chromosomal transposition of PiggyBac in mouse embryonic stem cells. Proc. Natl Acad. Sci. USA 105, 9290-9295 (2008).

48. Meier, I. D. et al. Short DNA sequences inserted for gene targeting can accidentally interfere with off-target gene expression. FASEB J. 24, 1714-1724 (2010).

49. Rad, R. et al. PiggyBac transposon mutagenesis: a tool for cancer gene discovery in mice. Science 330, 1104-1107 (2010).

50. Markel, P. et al. Theoretical and empirical issues for marker-assisted breeding of congenic mouse strains. Nat. Genet. 17, 280-284 (1997).

51. Suemizu, H. et al. Establishing EGFP congenic mice in a NOD/Shi-scid IL2Rg (null) (NOG) genetic background using a marker-assisted selection protocol (MASP). Exp. Anim. 57, 471-477 (2008).

52. Myung, J. et al. GABA-mediated repulsive coupling between circadian clock neurons in the SCN encodes seasonal time. Proc. Natl Acad. Sci. USA 112 E3920-E3929 (2015).

53. Ota, T. et al. Angiotensin II triggers expression of the adrenal gland zona glomerulosa-specific 3beta-hydroxysteroid dehydrogenase isoenzyme through de novo protein synthesis of the orphan nuclear receptors NGFIB and NURR1. Mol. Cell. Biol. 34, 3880-3894 (2014).

54. Lee, C., Weaver, D. R. \& Reppert, S. M. Direct association between mouse PERIOD and CKIepsilon is critical for a functioning circadian clock. Mol. Cell. Biol. 24, 584-594 (2004).

55. Yoshitane, H. et al. CLOCK-controlled polyphonic regulation of circadian rhythms through canonical and noncanonical E-boxes. Mol. Cell. Biol. 34 1776-1787 (2014).

56. Seluanov, A., Vaidya, A. \& Gorbunova, V. Establishing primary adult fibroblast cultures from rodents. J. Vis. Exp. 44, e2033 (2010).

57. Fustin, J. M. et al. RNA-methylation-dependent RNA processing controls the speed of the circadian clock. Cell 155, 793-806 (2013).

58. Yamazaki, S. \& Takahashi, J. S. Real-time luminescence reporting of circadian gene expression in mammals. Methods Enzymol. 393, 288-301 (2005).

59. Doi, M. et al. Gpr176 is a Gz-linked orphan G-protein-coupled receptor that sets the pace of circadian behaviour. Nat. Commun. 7, 10583 (2016).

60. Doi, M. et al. Circadian regulation of intracellular G-protein signalling mediates intercellular synchrony and rhythmicity in the suprachiasmatic nucleus. Nat. Commun. 2, 327 (2011).

61. Kiessling, S., Eichele, G. \& Oster, H. Adrenal glucocorticoids have a key role in circadian resynchronization in a mouse model of jet lag. J. Clin. Invest. 120, $2600-2609$ (2010).

\section{Acknowledgements}

We thank A. Bradley (Wellcome Trust Sanger Institute, UK) and Y. Nakajima (National Institute of Advanced Industrial Science and Technology, Japan) for providing ROSA26- 
PBase knock-in mice and Bmall-Eluc mice, respectively. This work was supported by the Core Research for Evolutional Science and Technology, Japan Science and Technology Agency (JPMJCR14W3), and the Ministry of Education, Culture, Sports, Science and Technology of Japan (15H05933, 17H01524, and 18H04015), and AMED Project for Elucidating and Controlling Mechanisms of Ageing and Longevity (JP17gm5010002, JP18gm5010002).

\section{Author contributions}

M.D. and H.O. conceived the project and designed the research; M.D., H.S. and Y.A. contributed equally as first authors who performed experiments in collaboration with I.M., H.H., Y.T., J-M.F., Y.Y., H.K., N.K., K.Y., C.L., M.A., K.S. and H.O.; M.D. and H.O. drafted the manuscript, supported by H.S., Y.A. and J-M.F.

\section{Additional information}

Supplementary Information accompanies this paper at https://doi.org/10.1038/s41467019-10532-2.

Competing interests: The authors declare no competing interests.

Reprints and permission information is available online at http://npg.nature.com/ reprintsandpermissions/
Journal peer review information: Nature Communications thanks the anonymous reviewer(s) for their contribution to the peer review of this work. Peer reviewer reports are available.

Publisher's note: Springer Nature remains neutral with regard to jurisdictional claims in published maps and institutional affiliations.

cC (i) Open Access This article is licensed under a Creative Commons Attribution 4.0 International License, which permits use, sharing, adaptation, distribution and reproduction in any medium or format, as long as you give appropriate credit to the original author(s) and the source, provide a link to the Creative Commons license, and indicate if changes were made. The images or other third party material in this article are included in the article's Creative Commons license, unless indicated otherwise in a credit line to the material. If material is not included in the article's Creative Commons license and your intended use is not permitted by statutory regulation or exceeds the permitted use, you will need to obtain permission directly from the copyright holder. To view a copy of this license, visit http://creativecommons.org/ licenses/by/4.0/.

(C) The Author(s) 2019 